\title{
Application of Satellite Data for Retrieving the Light Absorption Characteristics in the Black Sea Waters
}

\author{
V. S. Suetin, S. N. Korolev ${ }^{凶}$ \\ Marine Hydrophysical Institute of RAS, Sevastopol, Russian Federation \\ 凶s.korolev@mhi-ras.ru
}

\begin{abstract}
Purpose. The work is aimed at studying the effects of light absorption in the Black Sea waters with due regard for the variations of its individual components, and how they are manifested in the NASA archival results of calculating the chlorophyll $a$ concentration obtained by processing satellite data using the universal operational method.

Methods and Results. The NASA archival data of the MODIS and SeaWiFS satellite instruments, and the values of the light absorption components (determined by the method of Generalized ocean color inversion model for retrieving marine inherent optical properties (GIOP)) related to yellow substance and phytoplankton were analyzed. In order to avoid possible manifestations of various distortions in the results of determining the remote sensing reflectance of the sea and in the products resulted from application of the GIOP method, only the specially selected and sufficiently reliable test data from two areas located near the Crimea Southern Coast and south of the Danube estuary were used.

Conclusions. In the considered examples with low content of chlorophyll $a$ in the seawater, the yellow substance plays a predominant role in light absorption in the spectrum blue part, whereas if the chlorophyll $a$ content is high, the phytoplankton contribution is dominant. The revealed relationship between the light absorption components related to yellow substance and phytoplankton significantly differs from that implicitly preset as a basis of the universal method (applied in NASA for the satellite data operational processing) for determining the chlorophyll $a$ concentration. This, in its turn, is manifested in the fact that the data on the chlorophyll $a$ concentration in the Black Sea stored in the NASA archive may be overestimated in case the chlorophyll $a$ concentration is low, and underestimated - in case it is high.
\end{abstract}

Keywords: Black Sea, satellite observations, optical characteristics, light absorption, MODIS, SeaWiFS, GIOP, phytoplankton, yellow substance

Acknowledgments: the work was carried out within the framework of the state task on theme No. 0827-2020-0002 "Development of methods of operational oceanology based on interdisciplinary studies of the processes of formation and evolution of the marine environment and mathematical modeling using remote and contact measurement data". The authors are grateful to the NASA GSFC satellite data processing group for the provided opportunity to use the empirical data.

For citation: Suetin, V.S. and Korolev, S.N., 2021. Application of Satellite Data for Retrieving the Light Absorption Characteristics in the Black Sea Waters. Physical Oceanography, [e-journal] 28(2), pp. 205-214. doi:10.22449/1573-160X-2021-2-205-214

DOI: $10.22449 / 1573-160 X-2021-2-205-214$

(c) V. S. Suetin, S. N. Korolev, 2021

(C) Physical Oceanography, 2021

\section{Introduction}

The space remote sensing data application in the visible range of spectrum permits to determine the numerical values of the optical characteristics of water in the sea. To meet this challenge, it is necessary to use special complex methods for processing and interpreting the results of measurements of radiation by equipment operating in space. The range of issues arising in this case is considered from a general viewpoint in [1-3].

The present paper is aimed at studying the light absorption effects in the Black Sea waters. For this purpose, some examples of the data analysis from the SeaWiFS and ISSN 1573-160X PHYSICAL OCEANOGRAPHY VOL. 28 ISS. 2 (2021) 
MODIS satellite instruments are given in [4, 5]. The results of studies of light absorption features in the Black Sea waters, obtained using field measurements, are shown in [68]. Within the framework of practical applications of optical models, variations in the absorption coefficient components caused by phytoplankton $a_{\mathrm{ph}}(\lambda)$ and yellow substance (together with detritus) $a_{\mathrm{dg}}(\lambda)$ ( $\lambda$ is the wavelength radiation) are taken into account. Such information is necessary in the study of ecological processes, modeling the conditions for the light field formation in the sea. The optical characteristics of the Black Sea waters undergo significant variability due to the variety of occurring processes and phenomena; therefore, it is useful to consider new examples of using satellite data for their study.

Reliable separate retrieval of the absorption coefficient components $a_{\mathrm{ph}}(\lambda)$ and $a_{\mathrm{dg}}(\lambda)$ from satellite measurements is a rather difficult task; nevertheless, there are methods for its solution $[1-3,5,6]$. The relevance of this task lies in the fact that the $a_{\mathrm{ph}}(\lambda)$ value is directly related to the most important indicator of the biological productivity of the sea - the chlorophyll $a$ concentration, while the light absorption component variations $a_{\mathrm{dg}}(\lambda)$ can be a hindrance for determining its content in water by satellite data. In addition, the light absorption by a yellow substance is of independent interest, since in the Black Sea waters it can make a significant contribution to the total absorption [4-8]. Earlier in [4, 5], the $a_{\mathrm{ph}}(\lambda)$ and $a_{\mathrm{dg}}(\lambda)$ values retrieval results in the deep-water part of the Black Sea were described; in this paper, new examples of analysis of observations of areas located closer to the coast are considered.

\section{Materials and Methods}

Instruments installed on the satellite register radiation of various wavelengths in the visible range going out into space; the results of these measurements depend on many variable factors, which in general should be considered as unknown parameters. To find their numerical values, it is necessary to carry out a chain of transformations of the initial data. For this purpose, methods and algorithms of different complexity can be used [1,3]. The results presented below were obtained using the data processing products of the SeaWiFS and MODIS (Aqua) instruments contained in the NASA archive (http://oceancolor.gsfc.nasa.gov/) using the Generalized ocean color inversion model for retrieving marine Inherent Optical Properties (GIOP) [2, 3]. The GIOP method is based on the search for a model description of the empirical spectral values of the remote sensing reflectance $R_{\mathrm{rs}}(\lambda)$, calculated at one of the first stages of satellite measurements processing during atmospheric correction. In this case, physical models that in functional form express the $R_{\mathrm{rs}}(\lambda)$ dependence on the light wavelength and on the content of the main impurities in water or their optical properties at some fixed $\lambda$, are used. In the GIOP method, light absorption variations in the sea are taken into account by two variable parameters, $a_{\mathrm{ph}}(443)$ and $a_{\mathrm{dg}}(443)$. One of the key elements of this method is the single-parametric representation of the spectral dependence $a_{\mathrm{ph}}(\lambda)$ as a chlorophyll $a$ concentration function based on the statistical model from [9]. To date, few direct studies of absorption characteristics have been carried out in the Black Sea, but the information available in the literature (see, e.g, [6-8]) does not contradict the model concepts used in the GIOP method. Strictly speaking, it is possible that in the sea areas under consideration, the optical properties of water have specific features that differ from those taken into account in the GIOP method, thereby further refinement of the results obtained using this method may be required. 
Results of satellite data processing by the GIOP method are available in the NASA archive in a convenient digital format without loss of spatial and temporal resolution. The archive files, among other parameters, contain $a_{\mathrm{ph}}(443)$ and $a_{\mathrm{dg}}(443)$, which can be used to calculate $a_{\mathrm{ph}}(\lambda)$ and $a_{\mathrm{dg}}(\lambda)$ for all other wavelengths using the GIOP model. Examples of the complete spectra of these values are given in [5].

In addition to the absorption parameters, chlorophyll $a$ concentration estimates are also considered below. $C_{a}$ will denote the results of its retrieval using the universal $O C 3 m$ method, which are contained in the NASA archive directly among the standard products for operational satellite data processing. As an alternative, designated as $C_{a 1}$, it is also useful to consider the results of chlorophyll $a$ calculation according to the model from [9] using the following formula: $C_{a 1}=222 a_{\mathrm{ph}}(443)^{1,64}$. As a rule, in the Black Sea, the values of $C_{a}$ and $C_{a 1}$ differ; it is interesting to compare them and understand the reasons for this difference.

During practical GIOP method implementation, a significant limitation is due to the fact that the results of $R_{\mathrm{rs}}(\lambda)$ determination often do not have a sufficiently high reliability [10-12], and this leads to a decrease in the reliability of the final $a_{\mathrm{ph}}(443)$ and $a_{\mathrm{dg}}(443)$ values. The reasons for these distortions are associated with the complexity of atmospheric correction, manifestations of a sun glint, errors in setting the calibration parameters of the device, etc. Note that the problem associated with the $R_{\mathrm{rs}}(\lambda)$ distortions is relevant not only for the Black Sea, but also for many other water areas [ 12-15].

At the same time, the sources of distortions, as a rule, are variable in nature, and therefore, in some cases, conditions sufficiently favorable for the GIOP method application can appear. Accordingly, in order to obtain reliable conclusions, it makes sense to analyze only specially selected situations with the most reliable $R_{\mathrm{rs}}(\lambda)$ values. The satellite measurement processing system implemented in NASA provides identifying and excluding from the number of usable samples with low reliability, but to improve the accuracy of the GIOP procedure results, it is useful to consider the requirements based on more stringent criteria formulated and tested in $[4,5]$, additionally.

These requirements are that within extended cloudless areas of the sea there are no sharp chaotic spatio-temporal fluctuations of all determined values, including atmospheric parameters, and false local correlations between the products of calculations of the characteristics of the atmosphere and sea water. In addition, a sufficiently accurate model simulation of the empirical spectra $R_{\mathrm{rs}}(\lambda)$ and the coincidence of the results obtained from the data of the SeaWiFS and MODIS instruments are required.

It is known that when implementing methods such as GIOP, effects associated with instability or ambiguity in the solution of a multidimensional optimization problem may appear. However, as a result of the additional verification carried out, it was found that such effects are not significant for the considered test examples.

Application of the listed criteria leads to a significant reduction in the amount of data suitable for detailed studying of the Black Sea. However, the experience shows that it remains possible to analyze some rather interesting demonstration examples. For 2002-2010 the NASA archive accumulated a large number of such surveys with 
SeaWiFS and MODIS (Aqua) instruments, which can be considered almost synchronous and reflects a wide variety of variability of the optical properties of water in various areas and in different years.

\section{Results and their Discussion}

As a first example, the results of surveys of the area near Crimea in June 2009 are considered. Fig. 1 shows schematic maps of the spatial $C_{a}$ distribution on June 19, 2009 and the sea surface temperature on June 18, 2009, based on the results of processing data from the MODIS device contained in the NASA archive for this area. As is known, in many situations, $C_{a}$ can differ markedly from the actual chlorophyll $a$ content in the Black Sea. However, from Fig. 1 it is possible to judge indirectly the spatial distribution of the optical properties of water in this area. The maps of this figure show a characteristic spatial image of coastal upwelling, in which an increase in the chlorophyll $a$ concentration is associated with a water temperature decrease [16, 17]. As a rule, when studying upwelling, contrasts in the water temperature field are primarily taken into account, but it is also useful to consider its manifestation in the light absorption characteristics.
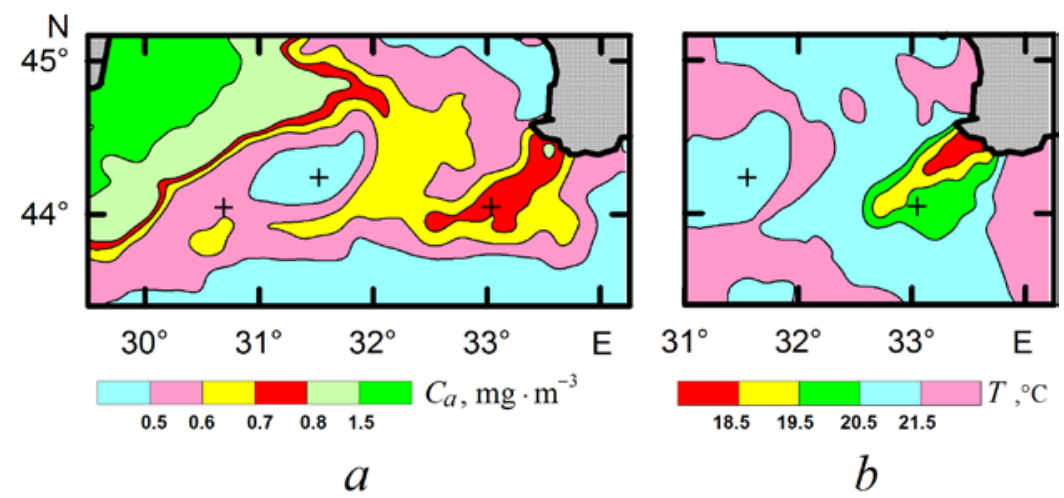

F i g. 1. Maps of spatial distribution of the $C_{a}$ value ( $a$ ) and the surface temperature $T(b)$ near Crimea on June 19 and 18, 2009, respectively. Crosses denote the positions of the analyzed test samples

Table 1 presents quite reliable results of retrieving the chlorophyll $a$ concentration and the optical parameters in the sea areas selected from the Fig. 1, carried out by the SeaWiFS instrument on June 19, 2009. In the NASA archive, this data is readings in single nodes of a regular coordinate grid (with a step of $\sim 9 \mathrm{~km}$ ) of the standard Level$3 m$ format. The $a_{\mathrm{ph}}(443)$ and $a_{\mathrm{dg}}(443)$ values in Table 1 for the wavelength $\lambda=443$ $\mathrm{nm}$ are quite indicative, and there is no need to consider them for other wavelengths. The results presented refer to the area $\left(44.04^{\circ} \mathrm{N} ; 33.04^{\circ} \mathrm{E}\right)$ with a low water temperature; in this area, $a_{\mathrm{ph}}(443)$ is 1.5 times higher than in neighboring areas. The contrast in the $a_{\mathrm{ph}}(443)$ field is not so great, but everywhere the yellow substance makes a predominant contribution to the total light absorption. This feature of the optical properties of Black Sea water should be taken into account when determining the total absorption spectra, as well as in a more accurate chlorophyll $a$ concentration calculation from the results of space measurements. The data in Table 1 generally reflect the spatial distribution of the considered parameters in the sea area shown in Fig. 1. The $C_{a}$ and $C_{a 1}$ values obtained here differ markedly, with $C_{a}>C_{a 1}$. In this case, 
in the $C_{a 1}$ field, the same picture of local contrasts as in the $C_{a}$ value map shown in Fig. 1 can be observed. The difference between them comes down to the difference in the general level and the imposition of insignificant distortions and fluctuations.

Table 1

\section{Results of retrieving the chlorophyll $a$ concentration and the optical parameters in the Black Sea waters, 19.06.2009}

\begin{tabular}{ccccccc}
\hline \multicolumn{2}{c|}{ Coordinates $^{\circ}$} & \multirow{2}{*}{$a_{\mathrm{ph}}(443), \mathrm{m}^{-1}$} & $a_{\mathrm{dg}}(443), \mathrm{m}^{-1}$ & \multirow{2}{*}{$C_{a}, \mathrm{mg} \cdot \mathrm{m}^{-3}$} & \multirow{2}{*}{$C_{a 1}, \mathrm{mg} \cdot \mathrm{m}^{-3}$} \\
\hline $\mathrm{N}$ & $\mathrm{E}$ & & 0.0447 & 0.47 & 0.19 \\
44.29 & 31.54 & 0.0134 & 0.0478 & 0.56 & 0.33 \\
44.04 & 30.71 & 0.0189 & 0.0503 & 0.71 & 0.47 \\
44.04 & 33.04 & 0.0230 & & \\
\hline
\end{tabular}

Regularities of values variations given in Table.1 are similar to those previously established in [5] from observations of the deep-water part of the Black Sea, and are characterized by relatively low values of $a_{\mathrm{ph}}(\lambda)$ and $a_{\mathrm{dg}}(\lambda)$; therefore, as another example, it is interesting to consider the results of area survey near the Danube mouth with significant spatial contrasts due to the outflow of river waters containing a large number of various impurities.
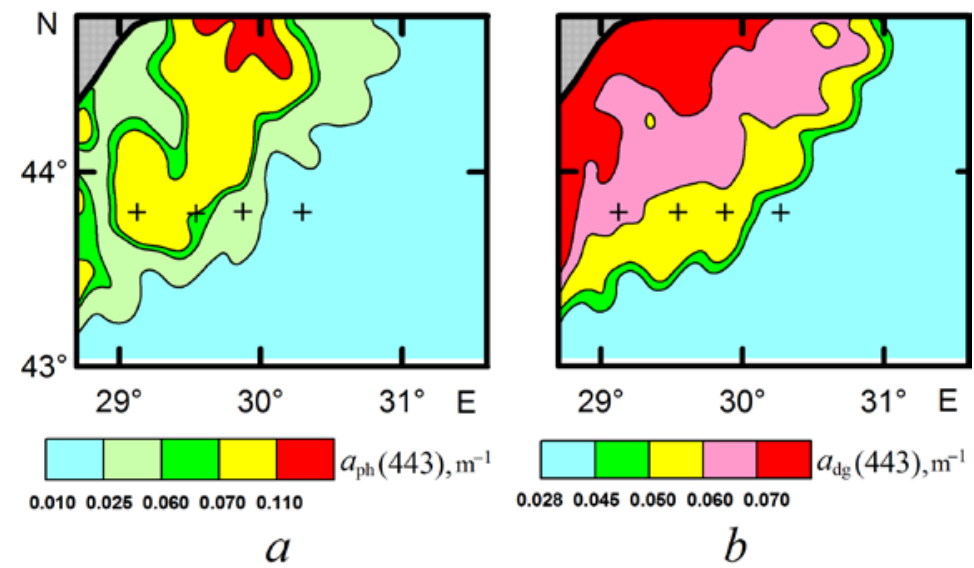

F i g. 2. Maps of spatial distribution of the $a_{\mathrm{ph}}(443)$ and $a_{\mathrm{dg}}(443)$ values near the Danube mouth constructed based on the MODIS (Aqua) data (12.08.2006). Crosses are the positions of the analyzed test samples

Fig. 2 shows maps of the spatial distribution of the $a_{\mathrm{ph}}(443)$ and $a_{\mathrm{dg}}(443)$ values in this area, created from the MODIS satellite imagery results on August 12, 2006. On these maps, a typical pattern of a river discharge with an increased level of light absorption parameters in water having a complex shape is shown. The results of processing satellite measurements related to four representative nodes of the Level-3m format coordinate grid from the area shown in Fig. 2 are given in Table. 
2. These data cover wide ranges of changes from practically the lowest values of the considered values found in the Black Sea to anomalously high ones, which are manifested near the coast and in the shelf zone.

Table 2

\section{Results of retrieving the chlorophyll $a$ concentration and the optical parameters in the Black Sea waters for August, 12, 2006}

\begin{tabular}{ccccccc}
\hline \multicolumn{2}{c|}{ Coordinates $^{\circ}$} & \multirow{2}{*}{$a_{\mathrm{ph}}(443), \mathrm{m}^{-1}$} & $a_{\mathrm{dg}}(443), \mathrm{m}^{-1}$ & $C_{a}, \mathrm{mg} \cdot \mathrm{m}^{-3}$ & \multirow{2}{*}{$C_{a 1}, \mathrm{mg} \cdot \mathrm{m}^{-3}$} \\
\hline $\mathrm{N}$ & $\mathrm{E}$ & & 0.0603 & 2.40 & 5.40 \\
43.79 & 29.13 & 0.1038 & 0.0595 & 1.69 & 2.60 \\
43.79 & 29.54 & 0.0662 & 0.0564 & 0.90 & 0.78 \\
43.79 & 29.88 & 0.0315 & 0.0388 & 0.43 & 0.22 \\
43.79 & 30.29 & 0.0147 & & \\
\hline
\end{tabular}

Their variation patterns in the range of low values are similar to those described above for the area located south of the Crimea coast. Here $a_{\mathrm{dg}}(443)>a_{\mathrm{ph}}(443)$ and $C_{a}>$ $C_{a 1}$. At higher values, the picture changes to the opposite $-a_{\mathrm{ph}}(443)$ becomes higher than $a_{\mathrm{dg}}(443)$, and $C_{a 1}$ exceeds $C_{a}$. In a visual form, the relationship between $C_{a}$ and $C_{a 1}$ for the test data from Table 2 is shown in Fig. 3. The coincidence of these values occurs when they are equal to $1 \mathrm{mg} \cdot \mathrm{m}^{-3}$.

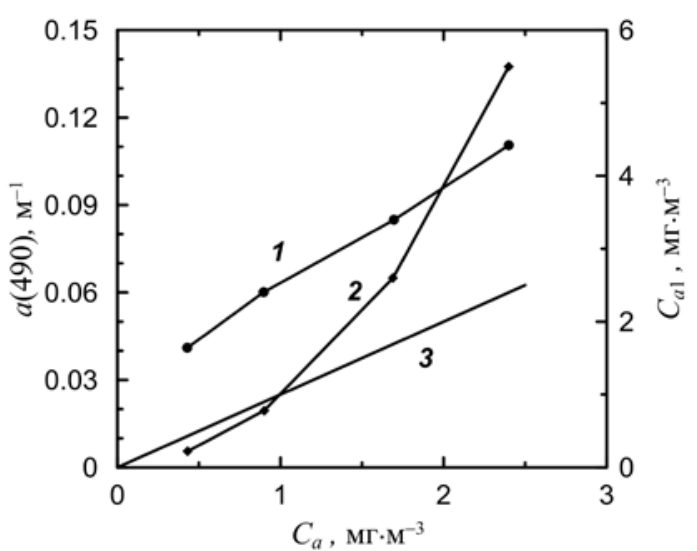

F i g. 3. Dependences of the $a(490)$ and $C_{\mathrm{a} 1}$ values on $C_{a}$ for the test data in Table. 2: $1-a(490) ; 2-C_{a 1}$ and $3-C_{a 1}=C_{a}$ (straight line)

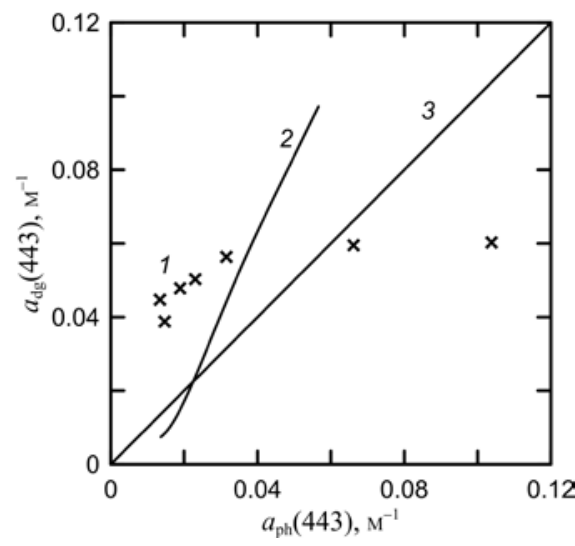

F i g. 4. Relation between the $a_{\mathrm{ph}}(443)$ and $a_{\mathrm{dg}}(443)$ values: 1 - based on the data from Tables 1 and 2; 2 - simulation results; 3 $a_{\mathrm{dg}}(443)=a_{\mathrm{ph}}(443)$ (straight line)

The $C_{a}$ values contained in the NASA archive are calculated according to a formal procedure through the spectral ratio $R\left(\lambda, \lambda_{0}\right)=R_{r s}(\lambda) / R_{r s}\left(\lambda_{0}\right)$ for two light wavelengths $\lambda$ and $\lambda_{0}$. Choice of the spectral channels to be used in this case depends on the $R\left(\lambda, \lambda_{0}\right)$ level, but this does not play a fundamental role [18]. Strictly speaking, such formulas are not able to provide an accurate account of all variable factors which the $R_{r s}(\lambda)$ values depend on, with their arbitrary independent variability. 
As is known, the $R\left(\lambda, \lambda_{0}\right)$ spectral ratio variations are mainly determined by variations in the light absorption in the sea $[19,20]$. Therefore, in its physical sense, the $C_{a}$ value differs from the real chlorophyll $a$ concentration. According to the same test data that are used in Table 2, Fig. 3 shows the relationship between $C_{a}$ and the total light absorption in water $a(490)$ at $\lambda=490 \mathrm{~nm}$. It is easy to see that a distinct close to linear relationship appears between these values. Since the NASA algorithm for chlorophyll $a$ concentration calculation switches between spectral channels, here the value $a(490)$ is taken instead of $a(443)$.

On the other hand, according to the physical sense, within the GIOP model framework, a one-to-one relationship between the chlorophyll $a$ concentration and $a_{\mathrm{ph}}(443)$ should be fulfilled. Therefore, the results of $C_{a}$ value calculation can be adequate to the real chlorophyll $a$ concentration values, only if the variations in the $a(\lambda)$ and $a_{\mathrm{ph}}(\lambda)$ values occur in such a way that a certain quite definite relationship is observed between them. The variable absorption components $a_{\mathrm{ph}}(\lambda)$ and $a_{\mathrm{dg}}(\lambda)$ should also be related in an appropriate way.

In the operational algorithm for processing satellite measurements $O C 3 m$ used in NASA, this relationship is taken into account implicitly as a result of the formal adjustment of the included coefficients. It's based on a statistical analysis of a large data array from direct test measurements of $R_{r s}(\lambda)$ and chlorophyll $a$ concentration in water so that as a result it is reflected generalized in the statistical sense the regularity of variability of conditions in the World Ocean. The corresponding functional relationship between $a_{\mathrm{ph}}(443)$ and $a_{\mathrm{dg}}(443)$ can be established by calculations using the GIOP model, taking into account the formulas used in this algorithm.

For this purpose, a series of model calculations was carried out. There the $R_{r s}(\lambda)$ spectra are calculated using the GIOP model on a sufficiently dense grid in the coordinates $\left\{a_{\mathrm{ph}}(443), a_{\mathrm{dg}}(443)\right\}$, and the calculated chlorophyll $a$ concentration values (for them designation $C_{a}(\mathrm{OC} 3 \mathrm{~m})$ is used ). Then, by direct enumeration of options on the grid, the such $a_{\mathrm{dg}}(443)$ values are determined, which the following equality is satisfied

$$
C_{a}(O C 3 m)=222 a_{\mathrm{ph}}(443)^{1,64}
$$

for all fixed input $a_{\mathrm{ph}}(443)$.

Additional test calculations indicate that variations in the scattering parameters can be neglected in this case. This is explained by the fact that the $O C 3 m$ algorithm includes the $R_{r s}(\lambda)$ ratio for $\lambda$ values close in the spectrum. The results of such calculations are shown in Fig. 4 by a solid line.

Within the ranges of variations of the analyzed optical parameters, corresponding to the studied conditions in the Black Sea, shown in Fig. 4, the curve is approximated with good accuracy by a $5^{\text {th }}$ degree polynomial with coefficients $0.048 ;-8.625 ; 585 ;-1.4743 \cdot 10^{4} ; 1.761410^{5} ;-8.11 \cdot 10^{5}$. According to this relation, at $a_{\mathrm{ph}}(443)<0.023 \mathrm{~m}^{-1}$, the condition $a_{\mathrm{ph}}(443)>a_{\mathrm{dg}}(443)$ is satisfied, and at higher values, on the contrary: $a_{\mathrm{ph}}(443)<a_{\mathrm{dg}}(443)$. According to the model described in [9], the transition value $a_{\mathrm{ph}}(443)=0.023 \mathrm{~m}^{-1}$ corresponds to the chlorophyll $a$ concentration of $\sim 0.45 \mathrm{mg} \mathrm{m}^{-3}$. Note that when obtaining such estimates, the model 
described in [9] was used. It corresponds to ocean waters of the so-called first type according to the well-known Morel classification [19].

For comparison, Fig. 4 also shows the data from Table 1 and 2 . The configuration of the corresponding set of points differs significantly from the relationship between $a_{\mathrm{ph}}(443)$ and $a_{\mathrm{dg}}(443)$, which is assumed in the algorithm for $C_{a}$ calculation used in NASA. This difference explains the reason for the difference by the values of $C_{a}$ and $C_{a 1}$ between those shown in Table 1 and 2 . As noted above, $C_{a}$ and $C_{a 1}$ coincide if they are equal to $1 \mathrm{mg} \cdot \mathrm{m}^{-3}$; this occurs when $a_{\mathrm{ph}}(443)=0.037 \mathrm{~m}^{-1}, a_{\mathrm{dg}}(443)=0.057 \mathrm{~m}^{-1}$. To find out the universality of the established regularities of the variability of the optical properties of the Black Sea water, further research is required.

\section{Conclusion}

Using satellite data from the NASA archive, obtained by the GIOP method processing, areas located near the southern coast of Crimea and south of the Danube mouth are considered. The analysis carried out helps the better understanding the features of the variability of the optical properties of water in the Black Sea. The analysis results show specific manifestations of variations in light absorption components associated with yellow substance and phytoplankton. The established relationship between these factors differs significantly from the one that is implicitly laid in the basis of the universal operational method used in NASA for determining the chlorophyll $a$ concentration in the upper water layer. In the considered examples with low content of chlorophyll $a$ in the seawater $\left(C_{a}<1 \mathrm{mg} \cdot \mathrm{m}^{-3}\right)$, the yellow substance plays a predominant role in light absorption with $443 \mathrm{~nm}$ wavelength, whereas if the chlorophyll $a$ content is high, the phytoplankton contribution is dominant.

The NASA algorithm gives adequate estimates of the chlorophyll $a$ concentration, in case the relationship between the absorption components has the opposite character at a low level, the main role is played by phytoplankton, and at a high level - by yellow substance. This, in its turn, is manifested in the fact that the data on the chlorophyll $a$ concentration in the Black Sea stored in the NASA archive may be overestimated in case the chlorophyll $a$ concentration is low, and underestimated - in case it is high.

\section{REFERENCES}

1. IOCCG, 2006. Remote Sensing of Inherent Optical Properties: Fundamentals, Tests of Algorithms, and Applications. Reports of the International Ocean-Colour Coordinating Group, No. 5. Dartmouth, Canada: IOCCG, 126 p. Available at: http://ioccg.org/reports/report5.pdf [Accessed: 11 March 2021].

2. Werdell, P.J., Franz, B.A., Bailey, S.W., Feldman, G.C., Boss, E., Brando, V.E., Dowell, M., Hirata, T., Lavender, S.J. [et al.], 2013. Generalized Ocean Color Inversion Model for Retrieving Marine Inherent Optical Properties. Applied Optics, 52(10), pp. 2019-2037. https://doi.org/10.1364/AO.52.002019

3. Werdell, P. J., McKinna, L.I.W., Boss, E., Ackleson, S.G., Craig, S.E., Gregg, W.W., Lee, Z., Maritorena, S., Roesler, C.S. [et al.], 2018. An Overview of Approaches and Challenges for Retrieving Marine Inherent Optical Properties from Ocean Color Remote Sensing. Progress in Oceanography, 160, pp. 186-212. https://doi.org/10.1016/j.pocean.2018.01.001

4. Suetin, V.S., Korolev, S.N. and Kucheryavy, A.A., 2014. Application of Satellite Observations for Determining Spectral Dependences of the Black Sea Waters Optical Characteristics. Morskoy Gidrofizicheckiy Zhurnal, (3) pp. 77-86 (in Russian).

5. Suetin, V.S. and Korolev, S.N., 2018. Estimating Specific Features of the Optical Property Variability in the Black Sea Waters Using the Data of SeaWiFS and MODIS Satellite 
Instruments. Physical Oceanography, 25(4), pp. 330-340. doi:10.22449/1573-160X-2018-4330-340

6. Burenkov, V.I., Kopelevich, O.V., Sheberstov, S.V., Ershova, S.V. and Evdoshenko, M.A., 1999. Bio-Optical Characteristics of the Aegean Sea Retrieved from Satellite Ocean Color Data. In: P. Malanotte-Rizzoli and V. N. Eremeev, eds., 1999. The Eastern Mediterranean as a Laboratory Basin for the Assessment of Contrasting Ecosystems. Dordrecht: Springer Science+Business Media, pp. 313-326. https://doi.org/10.1007/978-94-011-4796-5_217

7. Churilova, T.Ya., Suslin, V.V. and Sosik, H.M, 2009. A Spectral Model of Underwater Irradiance in the Black Sea. Physical Oceanography, 19(6), pp. 366-378. https://doi.org/10.1007/s11110-010-9060-8

8. Organelli, E., Claustre, H., Bricaud, A., Barbieux, M., Uitz, J., D'Ortenzio, F. and Dall'Olmo, G., 2017. Bio-Optical Anomalies in the World's Oceans: An Investigation on the Diffuse Attenuation Coefficients for Downward Irradiance Derived from Biogeochemical Argo Float Measurements. Journal of Geophysical Research: Oceans, 122(5), pp. 3543-3564. doi:10.1002/2016JC012629

9. Bricaud, A., Morel, A., Babin, M., Allali, K. and Claustre, H., 1998. Variations of Light Absorption by Suspended Particles with Chlorophyll a Concentration in Oceanic (Case 1) Waters: Analysis and Implications for Bio-Optical Models. Journal of Geophysical Research: Oceans, 103(C13), pp. 31033-31044. https://doi.org/10.1029/98JC02712

10. Suetin, V.S., Tolkachenko, G.A., Korolev, S.N. and Kucheryavy, A.A., 2013. Optical Features of Aerosols and Atmospheric Correction of Satellite Observations of the Black Sea. Morskoy Gidrofizicheckiy Zhurnal, (1), pp. 34-44 (in Russian).

11. Suetin, V.S., Korolev, S.N. and Kucheryaviy, A.A., 2016. Sun Glint Manifestation at Evaluating the Black Sea Water Optical Parameters using Satellite Measurements. Physical Oceanography, (3), pp. 47-56. doi:10.22449/1573-160X-2016-3-47-56

12. Kopelevich, O.V., Burenkov, V.I., Ershova, S.V., Sheberstov, S.V. and Evdoshenko, M.A., 2004. Application of SeaWiFS Data for Studying Variability of Bio-Optical Characteristics in the Barents, Black and Caspian Seas. Deep Sea Research Part II: Topical Studies in Oceanography, 51(10-11), pp. 1063-1091. doi:10.1016/j.dsr2.2003.10.009

13. Bailey, S.W. and Werdell, P.J., 2006. A Multi-Sensor Approach for the On-Orbit Validation of Ocean Color Satellite Data Products. Remote Sensing of Environment, 102(1-2), pp. 12-23. https://doi.org/10.1016/j.rse.2006.01.015

14. Hu, C., Feng, L. and Lee, Z., 2013. Uncertainties of SeaWiFS and MODIS Remote Sensing Reflectance: Implications from Clear Water Measurements. Remote Sensing of Environment, 133, pp. 168-182. https://doi.org/10.1016/j.rse.2013.02.012

15. Antoine, D., d’Ortenzio, F., Hooker, S.B., Bécu, G., Gentili, B., Tailliez, D. and Scott, A.J., 2008. Assessment of Uncertainty in the Ocean Reflectance Determined by Three Satellite Ocean Color Sensors (MERIS, SeaWiFS and MODIS-A) at an Offshore Site in the Mediterranean Sea (BOUSSOLE project). Journal of Geophysical Research: Oceans, 113(C7), C07013. https://doi.org/10.1029/2007JC004472

16. Goryachkin, Yu.N., 2018. Upwelling nearby the Crimea Western Coast. Physical Oceanography, 25(5), pp. 368-379. doi:10.22449/1573-160X-2018-5-368-379

17. Gawarkiewicz, G., Korotaev, G., Stanichny, S., Repetin, L. and Soloviev, D., 1999. Synoptic Upwelling and Cross-Shelf Transport Processes along the Crimean Coast of the Black Sea. Continental Shelf Research, 19(8), pp. 977-1005. https://doi.org/10.1016/S02784343(99)00003-5

18. O'Reilly, J.E. and Werdell, P.J., 2019. Chlorophyll Algorithms for Ocean Color Sensors - OC4, OC5 \& OC6. Remote Sensing of Environment, 229, pp. 32-47. https://doi.org/10.1016/j.rse.2019.04.021

19. Morel, A., 1980. In-Water and Remote Measurements of Ocean Color. Boundary-Layer Meteorology, 18(2), pp. 177-201. https://doi.org/10.1007/BF00121323 
20. Suetin, V.S., Suslin, V.V., Korolev, S.N. and Kucheryavyi, A.A., 2002. Analysis of the Variability of the Optical Properties of Water in the Black Sea in Summer 1998 According to the Data of a SeaWiFS Satellite Instrument. Physical Oceanography, 12(6), pp. 331-340. https://doi.org/10.1023/A:1021729229168

About the authors:

Vadim S. Suetin - Leading Research Associate, Marine Hydrophysical Institute of RAS (2 Kapitanskaya str., Sevastopol, 299011, Russian Federation), Ph.D. (Phys.-Math.), SPIN-code: 57966883, ORCID ID: 0000-0001-7278-667X, ResearcherID: M-6879-2018, v.suetin@mhi-ras.ru

Sergey N. Korolev - Junior Research Associate, Marine Hydrophysical Institute of RAS (2 Kapitanskaya str., Sevastopol, 299011, Russian Federation), SPIN-code: 9420-9479, ORCID ID: 0000-0001-5704-8863, ResearcherID: M-6584-2018, s.korolev@mhiras.ru

Contribution of the co-authors:

Sergey N. Korolev - computer implementation of algorithms, development and debugging of the computer program for solving the problem, works on PC, discussion of the results, construction of the tables, graphs and diagrams; the text revision

Vadim S. Suetin - scientific supervision, the problem setting out and formulation, development of mathematical model, the methodology development, qualitative analysis of the results and their interpretation, making conclusions, reference selection and analysis, preparation of the text of the article, writing the summary

All the authors have read and approved the final manuscript.

The authors declare that they have no conflict of interest. 